\title{
The impact of Technological innovation and Business Model Innovation on Venture Capital Intention
}

\author{
Beibei Gao ${ }^{1, a}$, Shushan Zhang ${ }^{2, b,{ }^{*}}$ and Qi Sun ${ }^{3, c}$ \\ ${ }^{1}$ School of Business, Northeast Normal University, Changchun, Jilin Province, China \\ 2 School of Business, Northeast Normal University, Changchun, Jilin Province, China \\ ${ }^{3}$ School of Business, Northeast Normal University, Changchun, Jilin Province, China \\ aBei_beigao@163.com, bZhangss591@nenu.edu.cn, ‘Qiisun@163.com \\ ${ }^{*}$ Corresponding author
}

Keywords: Technological innovation, Business model innovation, Venture capital intention.

\begin{abstract}
This paper analyzes the impact of business model innovation on venture capital intention and the moderating role that technological innovation plays between them in the process of technology entrepreneurship projects financing. The paper proposes that: business model innovation is significantly positively related to venture capital intention; technological innovation plays an inverted U- moderating role in the relationship.
\end{abstract}

\section{Introduction}

Under the background of "mass entrepreneurship and innovation", innovation and entrepreneurship have become hot topics for all walks of life, and the entrepreneurial boom has begun. In the process of entrepreneurship, entrepreneurs need strong financial support. Investors need to evaluate entrepreneurial projects and generate investment intention. Many scholars have established the evaluation index system of venture capital projects. Existing research shows that technology, product, market, and entrepreneurs' traits are all indispensable factors in the venture capital projects evaluation [1,2]. In order to win the favor of investors, start-ups must make innovation in these areas. Many scholars believe that entrepreneurship should be characterized by innovation and emphasize that entrepreneurs must continue to innovate. They hold that innovation is the essence of entrepreneurship and entrepreneurship is the process of innovation. In the early days, Schumpeter proposed that innovation should be a criterion for judging entrepreneurship. Drucker pointed out that innovation is a tool for entrepreneurship. With the development of the internet information technology, it is difficult to rely solely on technological innovation to establish a foothold in the market. Business model innovation has attracted more and more attention. Existing studies have shown that business model innovation has a significant positive effect on corporate performance. For technology entrepreneurship projects, technology has always been crucial, and the degree of technological innovation may affect the role of business model innovation. Therefore, this paper taking the technological innovation as moderating variable, proposes a theoretical model about the relationship between business model innovation and venture capital intention of technology entrepreneurial projects.

\section{Building the theoretical model}

\subsection{Business model innovation and venture capital intention}

Business model innovation is the process in which enterprises change their logic of value creation and value acquisition and provide new value propositions for customers through new resource integration methods and business processes [3].Wang and Dong consider that business model innovation create new organizational activities and architecture for value creation, transmission and acquisition [4]. Cucculelli and Bettinelli conducted an empirical 
study of 376 Italian SMEs and the result shows that business model innovation is critical to corporate performance, especially in maintaining sales growth [5]. Chinese scholars Cai and Dang conducted an empirical research on 151 emerging technology companies and founded that business model innovation can significantly promote corporate financial performance [6]. Luo, Xiang, Ning and Cheng investigated Chinese start-up companies and explored the impact of business model innovation on performance which includes profitability and growth [7]. And the results both showed that there was a significant positive correlation between them. Therefore, we hypothesize:

H1: Business model innovation has a positive effect on venture capital intention in technology entrepreneurship projects

\subsection{The moderating role of technological innovation}

The concept of "innovation" was first proposed by the economist Schumpeter. On the basis of summarizing China and foreign researches, Chinese scholar Chen proposed that technological innovation is a creative implementation of new products or services and it introduces new elements into the organization's production process and service operations [8]. Bayus believe that technological innovation can bring about the differentiation of products and services and increase market competitiveness [9]. Undoubtedly, investors are extremely concerned about products and markets. Therefore, technological innovation can affect the investment intention of venture capital. The first investment project evaluation system established by Tyebjee and Bruno emphasizes the uniqueness of market and products, and measures product uniqueness using the indicators of technical capabilities and patent protection [10]. Li and Zhou took technological small and medium startups as their research objects and built a risk investment evaluation system [11]. They believed that technological innovation capability was the focus of evaluation. This shows that the relationship between business model innovation and venture capital intention may be affected by technological innovation. Researches about the relationship of technological innovation and business model innovation focus on the cooperation and coupling research. Some scholars hold that technological innovation affects the choice of business model innovation. And some others believe business model innovation can promote technological innovation [12]. The choice of business model will affect the way of technology development and monetization, and be affected by technical characteristics and technical requirements in turn. Obviously, the impact between technological innovation and business model innovation is mutual. Business model innovation can make technology innovation better commercialized and realize its potential value. And the characteristics of technology itself and the need of technology commercialization will affect the choice of business model. Technological innovation and business model innovation are two important innovation subsystems. The benign cooperation of them will affect the enterprise's profitability and sustainable development. Good technological innovation and business model innovation means that entrepreneurial enterprises have greater development potential. Based on this, this study believes that technological innovation can strengthen the impact of business model innovation on venture capital intention.

Most of the existing studies have shown that the strengthening of technological innovation should be linear, which means the higher the degree of technological innovation, the stronger the impact of business model innovation on venture capital intention. However, the dependent variables of previous studies are mostly corporate performance and that of this study is the investment intention of venture capital. The willingness of investors to participate in the startups' management will also affect their investment intention. After investing in start-up companies, venture capital can participate in its subsequent strategic and operational activities and be the designer of business model [13]. When the level of technological innovation is high, investors will focus more on technology and have higher willingness to participate in management. Therefore, this study believes that technological innovation has a non-linear role in regulating the relationship of business model innovation and venture capital intention. 
Within a certain range, the moderating role of technological innovation increases as the increase of innovation degree. When technological innovation reaches a higher point, the importance of business model innovation is relatively reduced and its impact on venture capital intention is weaken, that is, as the degree of technological innovation increases, the positive impact of business model innovation on venture capital intention increases first and then weakens. Therefore, we hypothesize:

$\mathrm{H} 2$ : Technological innovation has an inverted U-shaped moderating role between business model innovation and venture capital intention.

Based on the above theoretical analysis and research hypotheses, this study constructed a theoretical model, as shown in Fig. 1.

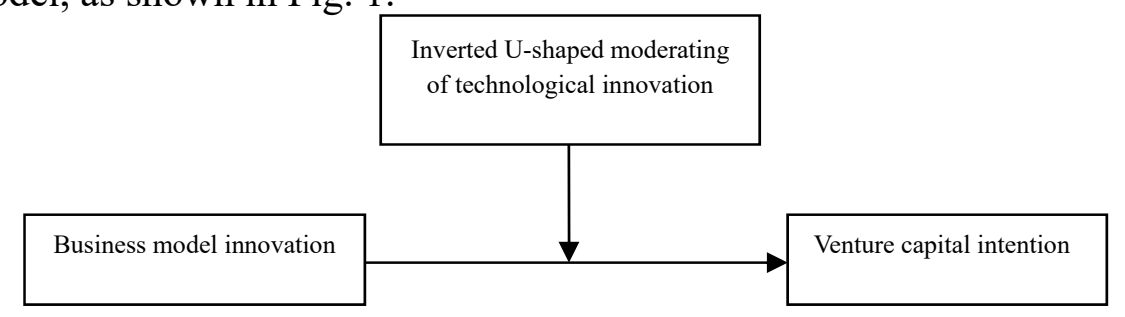

Fig. 1 Theoretical model

\section{Summary}

This paper constructs a theoretical model that business model innovation influences the venture capital intention, technological innovation has an inverted U-shaped moderating role between business model innovation and venture capital intention. This paper enriches the research in the field of innovation and venture capital investment. We will Track other related researches in the future.

\section{Acknowledgement}

This research was financially supported by the National Social Science Foundation of China (Grant NO. 18BJY180).

\section{References}

[1] Q. Yang, Y. Li, L.S. and Yin, Compositive Assessment Model of Venture Enterprises' Investment Value Based on Grey Theory, Journal of Wuhan University of Technology, Vol.4, pp.495-498, 2005.

[2] J. Su, High-Tech Enterprise Risk Investment Evaluation Study, Science \& Technology Progress and Policy, Vol. 9, pp. 124-127, 2013.

[3] M. W. Johnson, C. M. Christensen, and H. Kagermann, Reinventing Your Business Model, Harvard Business Review, Vol. 12: pp. 50-59, 2008.

[4] X. D. Wang, D. H. Dong, Review and Prospect of Research on Conceptual Innovation of Business Model, Foreign Economics and Management, Vol. 11, pp. 29-36, 2013.

[5] M. Cucculelli, C. Bettinelli, Business models, intangibles and firm performance: evidence on corporate entrepreneurship from Italian manufacturing SMEs, Small Business Economics, Vol. 45, pp. 329-350, 2015.

[6] J. Y. Cai, X. H. Dang, Business Model Innovation and Firm Performance: Evidence from Emerging Technological Firms, Operations Research and Management Science, Vol. 24, pp. 272-280, 2015. 
[7] X. W. Luo, G. P. Xiang, P. Ning, and C. Cheng, The impact of BMI on new venture performance: The effects of legitimacy and policy orientation, Studies in Science of Science, Vol. 7, pp. 1073-1084, 2017.

[8] J. Chen, C. Zhao, X. Jia, and L. Mei, Reconstruction Firm's technological innovation ability evaluation system: from knowledge management to value creation, Technology Economics, Vol. 36, pp. 1-8, 2017.

[9] B. L. Bayus, G. Erickson, and R. Jacobson, The Financial Rewards of New Product Introductions in the Personal Computer Industry, Management Science, Vol. 49, pp. 197-210, 2003.

[10] T. T. Tyebjee, A. V. Bruno, A model of Venture Capitalist Investment Activity, Management Science, Vol. 9, pp. 1051-1066, 1984.

[11] E. P. Li, X. Z. Zhou, Research on the Performance Evaluation Index System of the Risk Investment in Small and Medium-sized Hi-tech Venture Enterprise, Commercial Research, Vol. 5, pp. 125-132, 2013.

[12] C. Linder, S. Seidenstricker, Pushing New Technologies through Business Model Innovation, International Journal of Technology Marketing, Vol.7,pp.231-241, 2012.

[13] Y. N. Gou, J. Dong, Influence of venture capital background on firms' technological innovation. Science Research Management, Vol. 35, pp. 35-42, 2014. 